\title{
Exchange studies in Porto Alegre
}

\section{Mikaela Kärki}

I am a law student at the University of Helsinki, Finland. I have been studying Portuguese for some years already, and last year I finally decided it was time to spend a semester in Brazil. Since my first time in Brazil, in 2005, I wanted to come back and spend a longer time in the country.

My faculty does not have an agreement with a Brazilian university, so I started looking for one on the internet. I found out that there was a good university in Porto Alegre, Universidade Federal do Rio Grande do Sul (UFRGS), and entered in contact with their International Office. Soon I received a reply stating all the documents I had to send in order to be accepted as a visiting student. Not a long time after I had sent my application, I received an e-mail saying that I had been accepted. I also received information about what I should do next, who my tutor was etc. I was really quite impressed with the process!

I was lucky to already have a flat arranged before arriving in Porto Alegre, sharing with two Brazilian students. They really helped me a lot in the beginning, when I did not know anything about the city. My student tutor, Iulia, also was of great help! I was quite lost with all the paperwork, but in the end it was all resolved and I was matriculated in the subjects I wanted.

I have only got two subjects here, since I also plan to work on my masters thesis. I am taking Direito da Integração and Direito Financeiro e Finanças. And, of course, I also assist the meetings of the study group of professor Claudia Lima Marques, which are always very inspiring! Through the study group, I have been offered various opportunities to assist guest lectures, etc. I find the study group a very good way to learn new things, and to get to know other students and professors. At times, in addition to the lectures and the study group, I also assist the post-graduate specialization course in Public International Law.

Before arriving, I already spoke Portuguese, so I did not find it hard to manage in everyday situations. Of course, I never had the opportunity to actually speak a lot of Portuguese back home, so it took me a while to become fluent. Now, after 2,5 months here, I feel I am managing well. But studying law in a foreign language is sometimes hard, since I am not used to the terminology... One thing that is really good, though, is that here you speak Portuguese with everyone, even with the other exchange students. There are not that many European exchange students here, so you really feel special. The Brazilian students are welcoming and very interested in other cultures. I am hoping to see a student from UFRGS studying at my University in Finland one day!

Porto Alegre is quite different from the other Brazilian cities I had visited before. Here you can really see the European heritage. I find the city an interesting mixture of Latin and European cultures. What I especially like is that the central areas of the city are accessible by foot. I have learned a lot about Brazilian culture during my stay here. In Finland, you mostly hear about beaches, samba and football, but there is actually a lot more to this very diverse country that is Brazil. 